\title{
Foreword to the English edition
}

Although between us we have published more than 400 works in many languages, this book is unusually important for us. In it we take a definite step towards achieving the supreme task of contemporary Marxism: laying the basis for a Capital of the modern epoch. Raymond Aron long ago reproached Marxists for lacking a Capital for the twentieth century (Aron 1969), and our work addresses that lack for the twenty-first. The questions it asks are: what method should be adopted for studying commodities, money, and capital in the epoch of late capitalism, and what should the corresponding theory be?

While this task may seem exceedingly ambitious, we stand on the shoulders of giants and aim to develop further what they accomplished. Those who have undertaken this methodological task include Vladimir Lenin, Rosa Luxemburg, Karl Kautsky, Nikolay Bukharin, Aleksandr Bogdanov, and Leon Trotsky; Soviet and Western Marxists of the mid-twentieth century; and in recent decades, a diverse range of neo-Marxists, post-Marxists, and analytical Marxists, as well as orthodox thinkers. A great wealth of ideas is also contained in the works of Russian thinkers, whose works are represented, in particular, in the journals Voprosy politicheskoj ekonomii (Problems in political economy; www.interpolitec.su) and Al'ternativy (AlternativesAl'ternativy; www.alternativy.ru). Between them, these rich contributions have laid the foundations for a new, integral Marxist theory that can address the challenges of the modern world. However, such a theory is yet to emerge. In this work, we seek to open the way to such a theory and methodology.

We are well aware of the difficulties that attend such ambitious attempts in an age in which it is almost bad form to attempt fundamental research, and most confine themselves to specialised works on narrow topics. The very few works in recent decades that have attempted an integral rethinking of the main arguments of Capital can be divided into two unequal groups: a small number of fundamental works by very well-known authors (Ernest Mandel, Paul Sweezy, and István Mészáros, for instance) and a 
considerably longer list of less well-known works whose content is not especially profound.

In a field staked out by such works, researchers who live and work in semi-peripheral countries, cut off from Western scholarship by linguistic and organisational barriers, have little chance of being accepted as serious scholars. They are far more likely to be viewed as graphomaniacs. Have we managed to escape this 'periphery trap'? Have we been able to take our place, to the degree required, in the context of the world Marxist thought of recent decades? To be honest, if we have succeeded in this, it is in nothing like full measure. Our work has been conducted mainly in the context of Russian thought. This is certainly our great shortcoming, but it is also an advantage. By comparison with our foreign colleagues, we are the legatees of the heritage of Soviet critical Marxism, a heritage that is little known outside our country. Its methodological and theoretical importance, we are convinced, is comparable to the legacy of Marxist thought elsewhere in the world. Further, we have not worked alone; the authors of this book are only two members of a post-Soviet school of critical Marxism whose members and works are more fully discussed later in this book.

This book is also significant to us for purely personal reasons. In it, we sum up a crucially important part of our work over the past few decades. It was probably no accident that the first Russian edition of this work appeared shortly before our fiftieth birthdays, while the third edition, in two volumes, coincided with our reaching our sixties. The fifth edition of the book was published in autumn 2019.

The point, of course, lies not in the dates as such but in the fact that, while we were still students, we set ourselves the task of investigating the origins and emergence of the 'realm of freedom' that is replacing, in however incomplete, haphazard, and contradictory a manner, the 'realm of necessity', the world of alienation. If this seems rather an odd way to describe the process of creating a Capital for the twenty-first century, let us explain.

The experience of the revolutionary changes of twentieth century, especially in our country, gave us critical insights into the complexity of progress. Progress in the USSR combined undoubted achievements with horrible crimes, and great hopes, which seemed quite reasonable, with great disappointments. This experience led us to reject a linear view of historical progress and explore the problems of the combination of progress and regress, evolution and involution, dead ends, stagnation and prematurity, and revolutions followed by setbacks.

At the same time, this experience confirmed for us the principle of the development of society through contradictions, in which revolutions which transform the old method of production into a new, more progressive one, are practically inevitably followed by regression, restoration, and rollback. 
Equally inevitably, however, they eventually lead to progress and the possibility of breakthroughs in the future.

We devoted the first decades of our research primarily to studying the fresh shoots of a new society and its economy. Important way stations in the progress of this work were our doctoral dissertations, which we defended on the eve of the dissolution of the USSR, and three monographs, entitled After the Market, The Political Economy of a Non-Existent Socialism, and The Key to the Economy of the Twenty-First Century, that were prepared for publication in 1991 but never appeared. The years that followed saw us turn to the anatomy of late (twenty-first-century) capitalism, without, however, abandoning our concern with the study of new manifestations of the 'realm of freedom'. We wrote a good many texts on this topic. Some of these writings have been published, while others are still to appear. For us, the present book is thus the result of long years of work.

Now for a few words on the sources, the subject, the method, and the structure of our book.

\section{Subject and method}

Twenty-first-century capital is devoted to studying the system of production relations of modern capitalism. It is, therefore, a text of a primarily methodological and theoretical character. The authors did not set themselves the task of analysing and summarising the immense masses of empirical information that can be and is gathered about the functioning of the modern world economy. This is not because such a task is beyond our powers. It is because a great deal of this work of analysing and summarising the immense masses of empirical information has already been performed by our predecessors. We have sought to make the greatest possible use of these results of earlier studies, while approaching them, naturally, from a critical post-Soviet Marxist standpoint.

Achieving this has been easier than it might have been because we have previously made an extensive comparative analysis of economic systems, and have written at length on the problems of 'globalisation'. Moreover, as professors in the graduate school of the Faculty of Economics at Lomonosov Moscow State University, we have covered the ground every year, teaching our students to analyse international statistical data in our course on comparing economies. Where, however, statistical information is important to our argument, we have included it.

The theoretical sources on which our book rests will be discussed later. Here we would merely like to clarify that we have relied above all on the works of classical and modern Marxists - on the books and manuscripts 
of Karl Marx himself, and on the works of Friedrich Engels, Vladimir Lenin, Rosa Luxemburg, György Lukács (who subjected classical Marxism to rethinking and substantial development in the fields both of the ontology of social being, and of analysis of the forms of social consciousness), Antonio Gramsci (whose theory of hegemony is especially important for us), and Jean-Paul Sartre (on the questions of alienation and the individual). All of these thinkers are present in the book in sublated form, their ideas having been 'digested' and reworked by the authors, even though direct references to their works are relatively few.

While the central topic of our book - the production relations of late capitalism - is clear, a couple of important clarifications may be made. Firstly, we do not study the production relations of any particular country. What we understand by 'twenty-first-century capital' are the transformations that the production relations of capitalism undergo as the process of the 'sunset' of the bourgeois mode of production unfolds. Accordingly, the immediate topic of our research is precisely these systemic transformations and how they change commodities, money, capital, and reproduction. These transformations, as we shall see, have a systemic character and logically condition one another. While the market is transformed into a totality dominated by what we call network structures and simulacra, this development is amplified by the transformation of money into virtual, fictitious capital. This leads to the formation of a complex system of relations that subordinates not only human labour power but also individuals' personal qualities to capital.

Secondly, although the immediate topic of our study is late capitalism, the authors also stress the fundamental importance of the 'sunset' of the realm of (economic) necessity that forms its context. Here it is necessary to concretise what we understand by 'late capitalism'. The concept of 'late capitalism' entered into academic circulation mainly from the second half of the twentieth century onwards, although it appeared earlier. 'Late capitalism' is the stage of development of the capitalist mode of production at which the latter's further progress is possible only through the controversial inclusion of post-capitalist elements (and, in particular, post-market elements, such as planning) relationships. The authors' position is closest to those of Mandel (1987) and Jameson (1991). So although we use the term 'twentyfirst-century capitalism' most often, it is practically synonymous with late capitalism as defined above. This is important for understanding the logic of our book. The characteristics and contradictions of late capitalism are examined in detail in Chapter 5. As is readily apparent to those who have perused the table of contents, our work broadly follows the course of the argument of Capital, going from a discussion of stages of development through markets, money, and capital to reproduction. This is no accident; 
as stated earlier, we set ourselves the task of investigating the transformations that the production relations studied by Marx a century and a half ago have undergone in today's world.

Our book has evolved over many years and, inevitably, in a somewhat unsystematic fashion. The text was conceived as an integral, systematic study with a tight structure based on the methodology that we reveal in the first chapter of the book. However, it actually grew more like a tree than a building and, moreover, like a tree tended by a gardener who was not particularly neat, and who was distracted by a variety of experiments. The result is that some branches of this 'tree' have grown to an unusual size, in the process taking on an an untidy and occasionally even unkempt appearance. Some of the branches, or sections, began to appear only when the book was on the point of being completed, and finished up as offshoots that may not be particularly sturdy, but which seem to us to have an indubitable vitality. Others, by contrast, ceased to engage the close attention of the authors, grew sickly, and remained as small, partly withered limbs extending from the main trunk of the work. In a number of cases, texts that were not related directly to its problematic were 'grafted' onto the book; these were ones that supplemented the strict course of the research or that showed how the methodology and theory set forward in the book 'functioned' in resolving important problems of the modern age.

As a result, this book has turned out to be something between logically structured research and a collection of preludes, postscripts, and digressions. Meanwhile, readers who are interested primarily in the present-day implications of theoretical constructs may turn their attention largely to the postscripts, where various results of our theoretical analysis that are important for understanding current problems come to light.

Finally, while we have aimed to maximise clarity and logic, experienced readers will notice that we have, like Marx, 'flirted' to a degree with Hegelian triads.

\section{The plan of the book}

This book integrates key sections of the fifth Russian edition of the two-volume work Global'nyy capital (Global capital) and has two main parts - the methodological and the theoretical. Part I, 'Methodology matters', includes four chapters. In Chapter 1, 'The methodology of Capital: Karl Marx, Evald Ilyenkov, and the dialectics of the twenty-first century', we stress that methodology is important (just as 'institutions matter' in contemporary 'new institutionalism'). Unlike many contemporary scholars, including Marxists, we make our case not only on empirical but also on methodological arguments. 
In the present work, these require on the one hand a critical analysis of works by Hegel, Marx, and other dialecticians, and on the other, of works by such theoreticians of postmodernism as Derrida (Derrida 1994) and Foucault (Foucault 1980, 2000, 2005).

We separate the elements in the methodology of Karl Marx that remain valid and require re-actualisation from those elements that are obsolete and require critical updating. The systematisation of these provisions, together with a discussion of the main directions of research in post-Soviet Marxism, provides a starting point for the post-Soviet school of critical Marxism (in post-Soviet left circles this legacy is referred to more and more often as 'Ilenkovist').

The proposed methodology re-actualises key provisions of the method of ascent from the abstract to the concrete and of the historical-genetic approach. It distinguishes the book fundamentally from all other studies of the market and of capital that have appeared in recent decades.

Chapter 2, 'From orthodoxy to the post-Soviet school of critical Marxism', provides an original 'portrait' of different trends in Soviet and post-Soviet Marxism, opening up for the English-language reader a previously unknown world of research. Special emphasis is placed on describing specific features of the post-Soviet school of critical Marxism, of which the authors are among the leaders. This school has become the object of special analysis in China, Germany, Italy, and other countries, where research articles and other publications have been devoted to it.

Unlike most modern works of social analysis that assume as self-evident a reliance on the methodology of positivism and postmodernism, our book sets out to show that these methods do not permit an understanding of the modern market and capital, and doom scholars to achieving no more than descriptions of external forms. In Chapter 3, 'Obsolete postmodernism: the dialectics of non-linear, multi-scenario social transformations', we argue their position with the help of an analysis of the causes and consequences of the dominance of positivism and postmodernism in the modern social sciences, and on this basis, make a constructive criticism of these trends.

The next section of Chapter 3 is devoted to criticism of the general expansion of economics and of its continuation, so-called 'economic imperialism'. We reveal the causes of its emergence and spread (the increasing subordination of not only economic but also all other spheres of human life to the market), as well as the negative consequences of this expansion for the development of economic theory and economic practice.

Continuing in this vein, and building on our innovations in the field of the dialectics of transformation, progress, and regression, in Chapter 4, 'What drives the development of technology and the economy: production relations vs. productive forces, social creativity vs. activism', we combine 
the original provisions that characterise the socio-economic transformations with issues of the socio-spatial (and not just the socio-temporal - the theory of formations) measurement of social being. This allows us, in particular, to hypothesise a possible succession of stages (genesis, developed state, 'sunset') and models (mutations) of a single pre-bourgeois mode of production (a curious detail: this is a hypothesis of Aleksander Buzgalin, not fully shared by Andrey Kolganov), explaining the diversity of historical forms of the latter. These conclusions emerged from a critical dialogue with 'world-system' analysis. These classic and new provisions of the social philosophy of Marxism allow us to make a constructive criticism of the 'civilisational approach' (for more details see (Buzgalin 2014) and to show that today's key issues, and in particular the specifics of Russian society, may be adequately explained without the use of this methodology.

In this chapter, we set out the socio-philosophical arguments underlying our proof of the main propositions put forward in the second part. The starting point for our argumentation consists of showing the difference between the Marxist periodisation of history and the well-known 'five-term formula' (this is a concept that is typical of Soviet textbooks on Marxism, according to which Marx distinguished five successive modes of production in history: primitive communism, slavery, feudalism, capitalism, socialism (or communism)), and the importance of understanding the nature of the world of (social) alienation (in Marx's terminology, pre-history, 'the realm of (economic) necessity') as a whole.

Part II, 'The market, money, and capital in the twenty-first century', includes five chapters. In Chapter 5, “"Late capitalism": stages of development' we show, on the basis of critical analysis of a broad range of sources and statistical comparisons, the development of the capitalist economy that brought it to the late capitalist stage, indicating the degree to which the market and capital have been replaced by post-market and post-capitalist relations. This permits an identification of the historical place and character of late capitalism as the space-time of the 'sunset' of the system of capitalist production relations. This allows us to define the nature of 'late capitalism' as a space-time negation of capitalist production relations within the framework of this system, and to provide a theoretically and historically grounded periodisation of this era. It runs as follows:

(1) The late nineteenth and early twentieth centuries witnessed the 'undermining' of the basics of capitalism (the appearance of national market regulation and its manipulation by major corporations), which has been identified as monopoly capitalism (imperialism).

(2) The decades of the mid-twentieth century (characterised by social reformism and its alter ego, fascism), the hallmark of which was the development of a system of social limitations on the market, can be 
classified in theoretical terms as the period of the undermining of the power of money.

(3) The era of neoliberal revenge, globalisation, and financialisation, understood as 'the negation of the negation', followed. During it, the usury and merchant capital that prevailed in the period of the initial accumulation of capital re-emerged, making this a period of 'accumulation through deprivation' (or 'accumulation through dispossession' in David Harvey's phrase (2004)).

(4) Finally, we have before us today the increasing development of forms of negative withdrawal of classic capitalist exploitation in the form of the mass use of 'human' and 'social' capital and assignments of intellectual rent arising from the exploitation by capital of all the cultural wealth of humanity.

The determining resources of progress become cultural phenomena that in their essence are unlimited (in particular, knowledge), and the space of creative activity (to denote this space we use the term 'creatosphere', which is explored in more detail in Chapter 9). Nature, meanwhile, should serve as an asset rather than as a source of raw materials. With this understanding, we explore new forms of goods, money, and exploitation, and their relation to the global problems of humankind.

In Chapter 6, 'The totalitarian market: networks and simulacra', we characterise the market of twenty-first-century capitalism by reference to English-language and Russian-language works and through our analysis of data.

In Chapter 7, 'Money in the twenty-first century: financialisation as a product of virtual fictitious financial capital', we demonstrate our conclusions through data that characterise the contradictions and the new quality of the modern financial market, and also through a critical and comparative analysis of major works on finance capital and financialisation.

Chapter 8, 'Capital of the twenty-first century', proposes a historical-genetic system, ascending from the abstract to the specific, conditioned by sociospatial contradictions of the forms and methods of exploitation of the worker by capital that are inherent in the global economy of the twenty-first century. From slave-like forms of personal dependence, the development of this system proceeds via the 'classical' forms of capitalist exploitation of the industrial worker, to the use of methods of generating and assigning monopolistic profits (as well as imperialist profits, based on the exploitation of the periphery), giving rise to significantly new relationships involving the exploitation of creative activity. In the latter case, we propose a hypothesis revealing the new nature of this relationship. We argue that the exploitation of the creative worker involves not merely the appropriation of the surplus value that he or she creates, but also the exploitation of a certain amount of the universal creative effort of mankind, of universal cultural wealth. 
This result, associated as a rule not with a (creative) worker but with a subject of intellectual property (the corporation), has no value, but has a certain price. This situation allows the owner of a creative corporation to obtain so-called intellectual rent.

On this basis, we demonstrate changes in the relationships of formal and real subordination by capital not only of the workforce, but also of the human individual, in particular of her or his free time. This study permits a constructive criticism of the categories of human and social 'capital', which in perverse form reflect real changes in the role of human beings and in their social relations within the modern economy. We show that the basis for these phenomena is the subordination of the personal qualities of a creative employee, and of solidarity relations, to the overall process of the reproduction of capital.

The conclusions of Part II are based on the analysis of data characterising the structure of the labour market in different countries, the dynamics of salaries of different social groups in comparison with the dynamics of corporate profits, as well as the generalisation of a number of existing studies on this subject.

Chapter 9, 'Twenty-first-century reproduction: inequality and the "useless economy", describes the new trends in the process of reproduction of capitalist production relations, based on contemporary development of productive forces of capitalism. As in all phases of capitalism, the processes of capital accumulation and of reproduction of capitalist production relations in twenty-first-century capitalism also remain arenas where contradictory class interests clash. However, today, capitalism cannot reproduce itself without the introduction of more and more non-capitalist elements into the system of reproduction of capital. Under the pressure of the needs of new productive forces, especially in the creatosphere, and of class struggle, from the first half of the twentieth century onwards capital started to participate (albeit only partially) in the reproduction of the labour force. At the same time, it also sought to displace the most part of expenditure on the formation of a highly skilled labour force onto the state budget and onto working people themselves.

Well before the onset of the current stage, capital, seeking new sources of expansion, was starting to use the savings of working people (through pension funds, the stock market, insurance system, bank deposits and loans, etc.) as the basis and source of capital accumulation. Where the balance of forces between labour and capital was not in favour of the working class, these tendencies resulted in higher levels of social inequality and, thus, in the growth of social costs, increasing the social problems confronting working people and their families. At the same time, the attempts of capital to utilise the possibilities of the creative economy is resulting in the growth of the 
'useless sector' of the economy. This tendency is most openly manifested in financialisation, in the overdevelopment of financial transactions, and in the growth of financial instability.

In the Conclusion, we return to our point of departure, the argument that methodology does indeed matter in criticising positivism and postmodernism for 'overloading' the dialectical method. We also elaborate the hypothesis of nonlinear transformations and of regression of economic systems. We then show the main results of our development of classic Marxist definitions of market, money, and capital. We show that twenty-first-century capital is characterised by the genesis of the totalitarian market of networks and simulacra. Another transformation is transformation of money: financialisation leads to the domination in modern economy of virtual fictitious financial capital. Finally, we conclude that now the 'classical' exploitation of the industrial worker is multiplied through the appropriation of intellectual rent: the new quality of the general law of capitalist accumulation and the growth of the useless sector of the economy.

At the end of the end, in a Postscript to the book entitled 'Limits of the market and capital', we have decided to provide a short intensive summary of our view on the self-negation of capitalism. Whereas in the Conclusion we stress the importance of a critique of the market-centric model of economic theory and show that the new technological revolution grows out of social contradictions and leads necessarily to post-market economic relations, in the Postscript we propose that theoretical innovations are required for an adequate investigation of the new world of creative work and of the knowledge-based society. These innovations are, in particular, new proofs of the antagonism between market and creativity.

The present English-language book is a product of co-authorship. This does not mean that all its chapters were written as 'compositions for four hands'. Most arose out of joint discussions, the results of which one or the other of us wrote up as a text that we then repeatedly discussed and corrected or which, in some cases, one of us rewrote anew. The book consists of excerpts from the fifth edition of our two-volume Global'nyy capital (Global capital; vol. 1: Methodology: Beyond Positivism, Postmodernism and Economic Imperialism (Marx Re-Loaded); vol. 2: Theory: The Global Hegemony of Capital and its Limits ('Capital' Re-Loaded)), which appeared in Russian in 2019 and has had a broad resonance among readers of that language. Since the release of the third edition in 2014-15, the book has received wide publicity in Russia, and has been reviewed in seven leading scholarly journals were published. The main ideas of Global'nyy capital were presented at international seminars, conferences, and forums in Beijing, Berlin, Cambridge, Helsinki, New York, Stockholm, and Vienna. Courses for 
students of master's and $\mathrm{PhD}$ programmes at the University of Cambridge, Beijing University, Lomonosov Moscow State University, New York University, and the University of Massachusetts (Amherst) have been based on the book.

Various sections of the book have been translated into English, Chinese, and other languages, and have appeared as articles. In Russia, Europe, the US, China, and elsewhere, a great deal of constructive, critical discussion of the main positions advanced in our book has led to important clarifications and elaborations on various points, which appeared in the form of articles (included in the list of references below). On the other hand, the book has also been radically abridged to less than a quarter of its original length, and citations of Russian-language sources have been curtailed to make our arguments more accessible to readers of English. At the same time, we have significantly reworked the text in many sections, not only adapting it to readers of English, but also expanding the argumentation, updating factual data, and introducing various new arguments.

A number of excerpts from the present edition have appeared previously in English, including:

Buzgalin, A.V., and Kolganov, A.I., 2011. 'Re-Actualising Marxism in Russia:

The Dialectic of Transformation and Social Creativity', International

Critical Thought, vol. 1, no. 3, pp. 305-23.

Buzgalin, A.V., 2012. review of Freedom and Justice: The Temptations for

Russia of a False Choice by Ruslan S. Grinberg, World Review of

Political Economy, vol. 3, no. 2, pp. 218-39.

Buzgalin, A.V., and Kolganov, A.I., 2013. 'The Anatomy of Twenty-First

Century Exploitation: From Traditional Extraction of Surplus Value to Exploitation of Creative Activity', Science and Society, vol. 77, no. 4, pp. 486-511.

Buzgalin, A.V., and Kolganov, A.I., 2013. 'Marx Re-Loaded: il dibattito russo' [Marx re-loaded: the Russian debate], Ponte, vol. 69, no. 5-6, pp. 8-33.

Buzgalin, A.V., and Kolganov, A.I., 2014. 'Political Economy of the Human

Being: Prolegomena', MANEKO (Journal of Corporate Management and Economics), vol. 1, pp. 26-33.

Buzgalin, A.I., and Kolganov, A.V., 2016. 'Critical Political Economy: The "Market-Centric" Model of Economic Theory must Remain in the Past - Notes of the Post-Soviet School of Critical Marxism', Cambridge Journal of Economics, vol. 40, no. 2, pp. 575-98.

Kolganov, A.I., and Buzgalin, A.V., 2010. 'Economic Crisis: Scenarios of Post-Crisis Development', Science and Society, vol. 74, no. 4, pp. 538-46.

The texts concerned appear in the present book in reworked form, adapted to the requirements of a single monograph. 
In bringing this extensive foreword to a close, we acknowledge that this work has had a difficult birth. There are dozens of different drafts, plans, and concepts of the book stored in our archives. Even now, we are dissatisfied with the state of many sections of it. We were unable to include hundreds of prepared extracts from sources, as well as important explanations and remarks connected with the contributions made by our predecessors and colleagues. Dozens of books that we selected but have not yet read are gathering dust on our shelves. On reflection, however, we have decided that we have to stop somewhere, and to present our colleagues with a result, since 'the best is the enemy of the good'.

This is the result that you, our respected readers, have before you. We await your critical comments. 
Aleksander Buzgalin and Andrey Kolganov - 9781526131461 Downloaded from manchesterhive.com at 04/26/2023 08:25:23AM 